\title{
Portuarios en lucha: de la huelga de 1966 a la demanda por un "puerto-fábrica" en Bahía Blanca
}

\author{
Ana Belén Zapata ${ }^{\mathbf{1}}$ \\ UBA - UNS - Conicet \\ aymarazapata@yahoo.com.ar
}

Proponemos en este artículo analizar aspectos singulares de la dinámica de uno de los conflictos obreros más relevantes en los años 60, como fue la huelga portuaria de finales de 1966. Nos centraremos en la reconstrucción histórica de dicho conflicto en el puerto de Ingeniero White, cercano a la ciudad de Bahía Blanca.

Esta huelga fue declarada como consecuencia de un conjunto de medidas que pretendieron reorganizar la actividad portuaria. El gobierno dictatorial de Juan Carlos Onganía había instaurado un nuevo régimen de "racionalización" del trabajo portuario, estructurado a partir de modificaciones que atentaron sobre formas de trabajo y organización de los trabajadores aboliendo "muchas ventajas laborales cuya obtención se remontaba a 1946" (James, 1990: 291). Esta lucha se produjo en el marco de otras contra las políticas de racionalización en el ámbito público que afectaron también directamente a los trabajadores ferroviarios y de la industria azucarera del Noroeste del país.

La protesta se organizó en distintas zonas portuarias, ocasionó la paralización del transporte marítimo y de la actividad exportadora que tenía a los estibadores como actores centrales a partir de sus tareas de carga y descarga de buques. La medida trajo aparejada por un lado la intervención del Sindicato Unido de Portuarios Argentinos (SUPA) y en contrapartida también la estructuración horizontal de coordinadoras de resistencia que -tras la ausencia de dirigencia gremial-actuaron en relación a sectores barriales de las zonas aledañas a puertos. Snitcofsky (2011: 53) dimensiona este conflicto entendiendo que "las huelgas portuarias de 1966 constituyen un caso paradigmático, por presentar

1. Este artículo es una reformulación de uno de los capítulos de mi tesis de doctorado titulada "Andamios de experiencias: Conflictividad obrera, vigilancia y represión en Argentina. Bahía Blanca, 1966-1976” (2014).

(Archivos, año VI, $\mathrm{n}^{\circ} 11$, septiembre de 2017, pp. 163-182) 
múltiples evidencias sobre los vínculos entre ámbitos laborales y espacio territorial". Y fue significativa porque dio cuenta de la capacidad de los portuarios "para articular una resistencia prolongada en un contexto fuertemente represivo y sin contar con el apoyo de la burocracia sindical" (idem: 67). Pozzi y Schneider (2000) coinciden en que esta huelga tuvo un profundo impacto, una extensión que superó los setenta dias; y una singularidad evidenciada en la organización horizontal -e independiente de las burocracias sindicales- que supo dirigir la lucha -por lo pronto en Buenos Aires- a partir de la "Coordinadora de Comités de Resistencia de Barrios y Hoteles" conocida como "Intervillas."

En este marco, encontramos significativa esta experiencia -y la del puerto de Ingeniero White en particular- porque más allá del desenlace de la huelga, la misma resultó un puntapié inicial para reclamos más profundos y medulares sobre condiciones y organización del trabajo portuario. Si bien el conflicto fue de carácter nacional frente a los intentos por "racionalizar" los puertos, la lucha en el plano regional derivó significativamente en reclamos de mayor alcance, en demandas tendientes a lograr la institucionalización de una estabilidad laboral que los portuarios no habian podido concretar.

Trabajaremos desde este eje de análisis y también con la pretensión de aportar a la construcción de nuevas explicaciones históricas respecto del pasado reciente y de cómo se vivieron en escalas de lo local procesos políticos de alcance nacional. Intentamos pensar cómo se yuxtaponen, cruzan e interrelacionan demandas, medidas de fuerza, actores sindicales, entendiendo que en la reconstrucción histórica las escalas deberian siempre asumirse y problematizarse. En este sentido abordaremos la dinámica del conflicto, atendiendo a los ejes de coordinación y/o disonancia en las instancias que marcaron esta lucha y sus prácticas en lo local, regional y nacional. Nos preguntamos ¿cuáles fueron las principales demandas locales en el marco de medidas que afectaron a distintos puertos del país?, ¿cómo contrastaron los momentos de la huelga entre la escala local y la nacional?, ¿cuáles fueron los efectos de esta lucha para los trabajadores a corto y largo plazo?, ¿qué aprendizajes trajo aparejada la misma?

$$
* * *
$$

El puerto de Ingeniero White se encuentra ubicado a pocos kilómetros de la ciudad de Bahía Blanca, al sudoeste de la provincia de Buenos Aires. Hacia mitad de los años 60, este complejo portuario se ocupaba de realizar tráficos de combustibles, de cereales y de carga en general -mayoritariamente fruta proveniente del valle de Río Negro y de Neuquén-. Sus orígenes databan de fines del siglo XIX, y para los 
años 60 tenía un calado que rondaba los 33 pies con marea alta, esto le otorgaba grandes posibilidades en materia de actividad marítima incluso mayores a las del mismo puerto de Buenos Aires. ${ }^{2}$

La contratación de estibadores en White se realizaba por intermedio de las agencias o empresas de estibaje. ${ }^{3}$ En aquella época, operaban en White empresas como Murchison S.A., Agencia Marítima Dodero S.A., Monacci Maritima, entre otras. ${ }^{4}$ A diferencia del espacio laboral fabril, la actividad portuaria se regía con formas de contratación precarias por su eventualidad y estacionalidad; esto demandaba una organización de los propios trabajadores para evitar los abusos, las designaciones arbitrarias y los favoritismos. Por esta razón los estibadores habian adoptado una forma de autogestión de las contrataciones utilizando turnos asignados de manera rotativa, a partir de un número que se entregaba a los agremiados. Los portuarios detallaban que para ingresar a trabajar al puerto "tenías que tener el número". El llamado "número rotativo" representó una forma de gestión y distribución del trabajo democrática y equitativa resuelta entre los propios trabajadores del SUPA. ${ }^{5}$ La meto-

2. Al respecto, en 1968, el ministro de Economía de la Provincia de Buenos Aires José María Dagnino Pastore (1968) señalaba algunas características concretas sobre el puerto de Ingeniero White: "Como puerto exportador de cereales [...] es el puerto de embarque más grande sobre la costa atlántica, al sur de Buenos Aires, constituyendo la salida natural de la producción cerealera de la parte austral de la Provincia de Buenos Aires y La Pampa, así como para la fruta del Valle del Río Negro. [...] El calado de acceso en circunstancias de marea alta alcanza a 33 pies, valor excepcional comparado con Buenos Aires (28 pies) o Rosario (23 pies) Como puerto exportador de frutas es de hacer notar que mientras en 1961 se exportaron 241.000 cajones, en 1968 se superará el nivel de 4.500 .000 cajones".

3. El trabajo del estibador -especialmente dentro de las bodegas- era insalubre. La constante aspiración del polvillo y de productos químicos en los cereales provocaba severos problemas respiratorios.

4. Estas agencias hacian tareas de intermediación entre los exportadores y los trabajadores, y gestionaban la contratación de los estibadores necesarios para realizar el trabajo de carga y descarga. Cfr. las publicaciones institucionales de Administración General de Puertos: Puerto de Bahía Blanca 1971 y Puerto de Bahía Blanca 1974-1975.

5. Sobre el trabajo portuario, Berrotarán sostiene: "Las características sobresalientes del sistema portuario tradicional eran la eventualidad y precariedad del trabajo. La contratación irregular en el tiempo y la duración de la relación entre el trabajador y la empresa finalizaba cuando se liquidaba el jornal. A lo largo del siglo múltiples estrategias intentaron amortiguar los efectos de esta relación, entre ellas el pase de la contratación al pie del barco a la aceptación de formar las cuadrillas con los estibadores sindicalizados. Esta práctica fue resistida por los empresarios, ya que daba un papel central al sindicato en la formación de las cuadrillas; con posterioridad en la década de 1970 se aceptó la figura del delegado sindical. Otro mecanismo fue el de garantizar que los mismos trabajadores formasen las cuadrillas hasta la finalización de las tareas" (2000: 326). 
dología regulaba el orden y la cantidad de personas necesarias para la carga o descarga de un buque, equiparaba entre sí a los estibadores en la posibilidad de acceso al trabajo; permitía cierta seguridad de empleo, en una labor que de por sí tenía altos grados de eventualidad.

\section{La huelga contra la reestructuración del trabajo}

Durante la dictadura de Juan Carlos Onganía se modificó el régimen laboral del trabajo en los puertos nacionales a partir de las leyes $16.971 \mathrm{y}$ 16.972 y el decreto 2.729. Los puntos más importantes de estos cambios fueron el surgimiento de la figura del "Capitán de puerto" designado por el Poder Ejecutivo y a cargo de la coordinación de las tareas portuarias, la habilitación durante las 24 horas del puerto y el no reconocimiento de la insalubridad de las tareas en un mayor pago de las mismas. El gobierno sostenía que la legislación anterior no permitía la habilitación permanente del espacio portuario, y que "la anomia" del régimen legal laboral -tras la actuación "incontrolada" de empresas dedicadas a la provisión de mano de obra- impactaba negativamente en la eficiencia del sistema portuario nacional en su conjunto. Además,

se establecía un aumento de los controles en el momento de la contratación fijando por ejemplo, pautas más estrictas para la inscripción en el registro donde se concedía la habilitación legal para el trabajo portuario. De esa forma, la participación en huelgas o cualquier otra forma de organización y protesta podía ser motivo suficiente para justificar la exclusión del registro mencionado. (Snitcofsky, 2011: 62)

Estas medidas tuvieron diálogo con otras que buscaron ubicar al país en un lugar preferencial dentro de un orden económico mundial. Se buscaba una mayor "competitividad" en el trabajo en áreas de gestión estatal como ser la actividad portuaria, el transporte ferroviario y la industria azucarera del Noroeste del país. ${ }^{6}$ Para ello, entre octubre y diciembre de 1966 se hicieron anuncios de cambios dentro de estos

6. Al respecto Silvia Nassif sostiene que, frente a las explicaciones históricas que se han formulado sobre el proceso de "racionalización" del onganiato en el ámbito de los ingenios azucareros, "puede considerarse que la salida que la dictadura ofreció a la crisis de superproducción implicó una regresión y mutilación de las fuerzas productivas de la provincia a través del cierre de ingenios y la reducción de cupos en la producción de azúcar" y que desde el onganiato se buscó transferir parte de la producción tucumana a industriales jujeños y concentrarla en "manos de los industriales Blaquier y Arrieta que desde 1960 recibian además el apoyo de grupos financieros de Estados Unidos y de capitales italianos" (2012: 97). 
sectores productivos. Se requerian puertos con mayor celeridad en la entrada y salida de barcos. Esto iba en relación con una meta de producir una "modernización" y "racionalización" más general en el sector estatal y la burocracia gubernamental (O'Donnell, 2009: 100), aunque también, "otro claro objetivo eran las empresas nacionales medianas que habían utilizado su acceso a las facetas políticas del Estado para obtener protección económica. [...] La determinación del nuevo régimen de controlar y si era necesario reprimir al movimiento laboral se hizo patente antes incluso de que se formulara el plan de Krieger Vasena" (James, 1990: 290-291).

Si bien durante los años 60 y 70 la prensa local bahiense publicó día a día los récords alcanzados con las exportaciones desde el puerto de Ingeniero White, desde el discurso "modernizador" se comenzó a plantear sistemáticamente la necesidad de "limpiar" un puerto ahora considerado "sucio" o "lento" ante la urgencia de agilizar el trasporte marítimo.

Las nuevas medidas afectaron directamente las condiciones de trabajo de los estibadores. Se establecieron 4 turnos continuos de 6 horas cada uno, repartidos en horarios de 7 a 13 , de 13 a 19 , de 19 a 1 y de 1 a 7 . De esa forma se habilitaba el puerto las 24 horas y se cubría toda la jornada. Para evitar los llamados "tiempos muertos" la nueva reglamentación estipuló que todas las actividades relacionadas con cambio de ropa, preparación del equipo de trabajo, apertura o cierre de bodegas se realizaran por fuera del horario de contratación. El gerente de elevadores y puertos de Ingeniero White, Víctor Pozzolo, explicaba que "el régimen establecido ahora fija seis horas en dos turnos para los trabajos insalubres y seis horas corridas para los no insalubres". ${ }^{7}$ Se detalló que, mientras que antes sobre 11 horas de trabajo corridas se abonaban hasta 5 jornales, a partir de la nueva normativa con 12 horas de trabajo se pagarian solo 2 jornales.

Luego de que la noticia de los cambios se hizo pública, Ismael Paiz -a la sazón, secretario general del SUPA del puerto Ingeniero White- declaró su abierto rechazo a la reestructuración. Y manifestó que había sido concebida "a espaldas de la organización obrera de los estibadores que es la pieza fundamental en la explotación económica de nuestro puerto". ${ }^{8}$

Los primeros signos de la reorganización en White se observaron con la llegada a Bahía Blanca del capitán de fragata José María Ochoa, quien asumió la Capitanía del puerto. Se preveía que para el 20 de octubre el nuevo régimen estaría funcionando plenamente. Sin embargo, el 19 de octubre a las cero horas los estibadores declararon una huelga por tiempo indeterminado, como medida de lucha frente al nuevo régimen.

7. La Nueva Provincia [LNP], 21 de octubre de 1966.

8. El Sureño, 11 de octubre de 1966. 
Ésta fue acatada de forma inmediata en los puertos de Dock Sud y Mar del Plata. En Bahía Blanca los estibadores recién se adhirieron al día siguiente luego de una gran asamblea donde votaron el acatamiento.

En consecuencia, el capitán Ochoa procuró dividir al colectivo de trabajadores de estiba fomentando la actividad de los rompehuelgas, anunciando que se cuidaria "la libertad de trabajo" eliminando del registro del personal de estiba a todos aquellos que no fueran a trabajar. Asimismo, se abrió el registro para quienes, sin figurar previamente en él, optaran por ir al puerto pese a la huelga. Aquel 20 de octubre toda la zona de White amaneció fuertemente vigilada por efectivos de la Prefectura que respondian a la Capitania. La prensa local anunciaba que el personal de Subprefectura "provisto de armas largas" habia estado vigilando el espacio portuario durante toda la jornada, y que "en los puertos locales había alrededor de 500 obreros con libretas de trabajo de los que sólo trabajaban poco más de un centenar". ${ }^{9}$

Schneider sostiene que "aunque el paro tuvo un alcance nacional, el núcleo dinámico del conflicto fue el puerto de Buenos Aires" (2005: 270). Podriamos matizar esta impresión analizando en cambio que hubo diversas dinámicas del conflicto que excedieron a los hechos capitalinos. En este sentido, incluso es posible pensar en diversas temporalidades si atendemos los hechos en distintas escalas espaciales, para el caso, los diversos puertos y no sólo el de Buenos Aires. ${ }^{10}$ En efecto, en White el día 21 se reunieron alrededor de 500 estibadores en asamblea para decidir cómo proseguirian la protesta que avanzaba en términos concretos en otros puntos. Alli los trabajadores resolvieron levantar la medida de fuerza. Es decir, mientras el paro se sostenía por tiempo indeterminado en Buenos Aires, los estibadores whitenses optaron por levantar la medida y volver a sus tareas en el turno de las 13 horas.

Al regresar al puerto se experimentaron situaciones de tensión. Con las nuevas disposiciones, las empresas de estibaje comenzaron a contratar personal desestimando las funciones de los delegados del SUPA y la organización que ellos coordinaban cotidianamente para el empleo por medio del turno rotativo hasta antes de la modificación del

\section{9. $L N P, 21$ de octubre de 1966.}

10. Reconstruir un proceso nacional atendiendo al diálogo constante entre diversas escalas de análisis no solo posibilita la ampliación del conocimiento sobre el mismo; también permite complejizar el análisis de los procesos y advertir el peligro de soslayar realidades locales/regionales al asumir la nacionalización de una realidad más acotada. Estas visiones "porteño-céntricas" ya vienen siendo revisadas desde numerosos estudios dentro del ámbito de la historia reciente que han problematizado la cuestión de las escalas de análisis en los últimos años (Águila, 2008 y 2015; Bandieri, 2008; Jensen, 2010; Rodríguez Agüero, 2013; Scatizza, 2013; Zapata, 2014 y 2015; Jensen y Lastra, 2015). 
régimen portuario. Los estibadores de White al levantar la medida de fuerza quedaron presos de las arbitrariedades del nuevo régimen que ya no consideraba válido el turno rotativo para el ingreso democrático al trabajo del día. Las medidas de Onganía abrieron una puerta hacia la clausura de la actividad de los delegados.

Frente a esto, los estibadores se reunieron y discutieron sobre la posibilidad de volver a un estado de huelga; decidieron declarar el paro por tiempo indeterminado en el puerto de Ingeniero White en reclamo "por la violación del turno rotativo y leyes de trabajo". Asimismo, Víctor Benamo (abogado del SUPA) presentó un recurso de amparo por violación al convenio colectivo firmado en el año 1961. Ismael Paiz recordaba los motivos por los cuales habian tomado esas determinaciones y el nivel de sobreexplotación que implicaron los cambios tras la quita del turno rotativo:

nos rompieron todas las conquistas que teníamos [...] Cada obrero teníamos un turno para entrar, un número. Entonces qué pasaba, de las 7 de la mañana a las 10 de la mañana entraba del 1 al 40 pongámosle... y ahí se cortaba porque no había más lugar para otro. De las 10, entraba del 40 al 60 . Entonces ese es el turno rotativo. Y eso nos lo sacaron todo, todo, todo. Después venía el capataz de la empresa y "hacía la gente" a dedo: vos, vos, vení vos... y así... ¿Y qué pasaba? Por ejemplo en la época en que teníamos el turno nosotros [...] se trabajaba bien, pero tranquilo a conciencia. Y cuando vinieron las empresas así con los capataces... Éramos 8 cuando trabajábamos normal nosotros éramos 8 . Ponía 4 personas por mano. En vez de 8, ponía $4 .{ }^{11}$

También, Paiz aclaró ante la prensa que el paro se había levantado antes con la intención de comenzar un "diálogo constructivo", pero ante la evidencia de que las empresas estaban tomando estibadores desestimando la función de los delegados, se resolvió esta nueva medida.

El paro por tiempo indeterminado implicó fuertes enfrentamientos entre los trabajadores del SUPA que estaban resistiendo por un lado y los "changarines" que decidieron ir a trabajar y suplir los lugares vacantes, por el otro. Por distintos medios se repudiaron estas acciones de los rompehuelgas.

Observamos que esta huelga, que a nivel nacional comenzó en repudio por la restructuración del régimen laboral de puertos en su conjunto, a nivel local se alzó de manera más rotunda y enfática en el reclamo por la pérdida de turno rotativo. Esto impactó entre los trabajadores y amplificó diferencias latentes entre agremiados y "changas" que comenzaron a

11. Entrevista de la autora a Ismael Paiz (estibador), 20 de julio de 2013. 
operar en muchos casos como "carneros". Los representantes del SUPA sostenían su firme posición en medios de prensa local:

Con el turno rotativo, los verdaderos estibadores se aseguran por parte de los patrones el ofrecimiento de trabajo, y por un simple número cada obrero sabe que, si concurre a la parada, va a ser llamado a trabajar y no como pretende la nueva reglamentación, o mejor dicho, los encargados de aplicarla que someten las posibilidades de trabajar solamente a la digitación de los capataces. ${ }^{12}$

En Buenos Aires, luego de que fuera intervenido el SUPA, la lucha pasó a ser dirigida por una coordinadora intersindical que reunió a distintos gremios de portuarios ${ }^{13}$-no solo estibadores- $y$ también a distintas agrupaciones dentro del SUPA como La Ligada, Cruzada Renovadora y Justicia y Verdad (Schneider, 2005: 270). La organización dentro del ámbito barrial luego se amplió a un nucleamiento más extenso, como fue la Coordinadora de Comités de Resistencia de Barrios y Hoteles o Coordinadora Intervillas (Schneider, 2005: 270; Snitcofsky, 2011: 65). En el plano internacional, la huelga recibió el apoyo de la Federación Internacional de Trabajadores de Transportes, que estipuló medidas de boicot para cualquier buque de procedencia argentina, en repudio por las medidas del gobierno con los portuarios y en apoyo al SUPA y a su dirigente, Eustaquio Tolosa, como miembro de dicha federación.

El 19 de diciembre el SUPA convocó a una asamblea de portuarios en el Luna Park; según anunciaban diarios de la época, la organización había resuelto levantar la huelga. La medida, que llevaba casi dos meses, se estaba sosteniendo en Buenos Aires por Intervillas, desde su organización barrial y de base con la ayuda popular. Según medios extranjeros "el levantamiento de la huelga se debe a las atinadas gestiones del señor Manuel Medrano, delegado de la Federación Internacional de Trabajadores del Transporte, quien al parecer habia logrado aceptables condiciones de arreglo en sus largas conferencias con el secretario de Trabajo, señor Rubens G. San Sebastián". ${ }^{14}$

El whitense Paiz participó de la multitudinaria asamblea en el Luna

12. El Sureño, 8 de diciembre de 1966.

13. La protesta en el puerto de Buenos Aires se extendió por dos meses. Sobre la organización y coordinación de esta lucha, Schneider mencionaba que "se constituyeron alrededor de veinte centros (o comisiones de resistencia) que en forma democrática condujeron durante un breve tiempo la protesta. Esta coordinadora, que pasó a ser denominada Intervillas [...] Intervillas, además de la medida de fuerza, tuvo que hacer frente a la dirigencia del sindicato" (2005: 271).

14. ABC, 20 de diciembre de 1966. 
Park como uno de los cientos de representantes del interior del país que asistieron al encuentro, que funcionó como lugar de contacto y comunicación de las experiencias locales de organización. Tras la intervención de la policía, el dirigente whitense recordó el momento cuando Tolosa fue capturado en medio de tiros y violentos forcejeos:

Nosotros por ejemplo viajamos ahí, en la huelga. En la huelga Tolosa tenía la captura. Porque lo mandaron a hacer un paro internacional. Y él estaba, creo que estaba en Montevideo, en Brasil o en Montevideo me parece que estaba...Había venido... no podía venir a Argentina, y se hizo una asamblea mayoritaria en el Luna Park, todos los puertos. Y cuando fuimos, todos los puertos fueron, jestaba lleno el Luna Park! (...) ¡Sabes el desbarajuste que se armó! La gente, yo por ejemplo, saltábamos las butacas de un lado para el otro...para escapar porque ¡todos con ametralladora la policía, llegó a tirar tiros! ${ }^{15}$

Respecto de este encuentro en el Luna Park, otro testigo de la jornada se refirió al desgaste y la desmoralización que ya influía en los ánimos de todos por aquellos dias:

Los compañeros estaban desmoralizados con tantos días y sin más ayuda que la que nosotros mismos nos proporcionábamos. Tolosa vuelve con el apoyo del gobierno, llama a una asamblea en el Luna Park para levantar la huelga; nosotros se la damos vuelta y entonces recurre a la policía. Entra la guardia de infantería al Luna Park y lo detiene. Entonces, el sindicato declara levantada la huelga. Intervillas pierde fuerza, porque los portuarios están desmoralizados, han sido traicionados. Así se pierde. ${ }^{16}$

Luego de la detención de Tolosa, días más tarde desde el SUPA se levantó la huelga.

En White, ese primer día de trabajo se caracterizó por la militarización total de la zona de embarque. El puerto se encontraba invadido de oficiales de Prefectura con perros y armas largas para intimidar a los estibadores. Además, esa mañana los portuarios que habian participado en la huelga constataron que ya no podrian ingresar al puerto a trabajar. Luego de ese momento, únicamente pudieron trabajar quienes

15. Entrevista de la autora a Ismael Paiz (estibador), 20 de julio de 2013.

16. Avanzada Socialista, n62, 7 de junio de 1973. Cfr. Schneider (2005: 273). 
tenían "en su poder la tarjeta plástica correspondiente o certificado de iniciación de trámite expedido por la prefectura". ${ }^{17}$

De todas formas, cabe destacar que en Bahía Blanca la lucha no concluyó -al igual que en Buenos Aires- el día 26 de diciembre. Porque luego de los hechos del Luna Park se reunieron más de 900 estibadores en una asamblea extraordinaria y se plantearon cómo proseguir con las medidas de fuerza a nivel local; es decir, si seguirian los pasos de los portuarios en Buenos Aires, o no. A mano alzada finalmente se votó, y por unanimidad decidieron continuar la huelga por tiempo indeterminado "hasta lograr que el gobierno derogue las nuevas disposiciones". ${ }^{18}$ Además, en esa asamblea, los trabajadores se manifestaron en repudio de las autoridades de la Confederación General del Trabajo por no haberse expedido antes, frente a la lucha.

\section{La lucha continuó: la toma de la CGT regional}

El reclamo hacia la central obrera tomó estado público cuando el 7 de enero de 1967 treinta portuarios tomaron el local de la CGT regional. A través de esta toma expresaron su repudio contra los dirigentes locales y nacionales de esta central. ${ }^{19} \mathrm{El}$ descontento se expresó también fuertemente desde el diario obrero El Estibador. ${ }^{20}$ Se consideraba que la CGT se había "entregado a las autoridades nacionales" y se había mantenido pasiva en medio de las distintas protestas y luchas que se venían dando en diferentes sectores". ${ }^{21}$

17. $L N P, 27$ de diciembre de 1966.

18. El Sureño, 27 de diciembre de 1966.

19. Esta toma de la CGT bahiense también puede ser considerada en relación a las antecedentes presiones en Buenos Aires ejercidas desde la Coordinadora de Intervillas, cuando en noviembre de 1966 se interpeló a la CGT nacional para que dispusiera medidas de apoyo a la huelga. La Coordinación Intervillas había manifestado la necesidad de un plan de lucha en conjunto con azucareros y ferroviarios que también estaban sufriendo las reformas del gobierno. Boletín de Huelga $\mathrm{n}^{\circ} 7$, noviembre de 1966. Cfr. Schneider (2005: 272).

20. El Estibador, 8 de febrero de 1967. El Estibador fue un periódico obrero producido por la agrupación local portuaria Unidad y Lucha, y dirigido por el estibador Aníbal Marziani.

21. Pese a la denunciada pasividad de la CGT local, la lucha de los portuarios en Bahía Blanca estuvo apoyada por diversos sectores gremiales y no gremiales en distintos momentos. Los estibadores en asambleas comunicaban las adhesiones. Tanto la Unión Ferroviaria de talleres Noroeste como de White expresaron su apoyo al SUPA, especialmente Luis Leiva (secretario general de UF White). Si bien en Buenos Aires el rol de La Ligada, Cruzada Renovadora y Justicia y Verdad fue muy importante, en Bahía Blanca no tenemos registros de una coordinación de la lucha con estas agrupaciones en concreto. Podemos mencionar en cambio, la importante participación 
No obstante, los estibadores aclaraban que la toma se realizaba de manera pacífica -aunque esa modalidad podía cambiar si se los intentaba sacar de allí-. Por otra parte, también reclamaban por la libertad de su dirigente nacional Eustaquio Tolosa, por medio de comunicados que decian:

Ante la situación creada reclamamos una gestión inmediata del secretariado de la CGT de Bahía Blanca, con la finalidad de aclarar su posición en la emergencia ordenando un programa de acción acorde con las circunstancias. [...] el sector obrero está dispuesto a ejercer la presión que crea conveniente para el logro de sus derechos. Las bases son las que actúan frente a la pasividad de la dirección. Tales son los objetivos y tal es la decisión que mantendremos. ${ }^{22}$

Frente a los hechos, Ezequiel Crisol, a la sazón dirigente local de la CGT, defendió la institución declarando públicamente que "en todo momento la delegación regional de la CGT ha prestado su solidaridad y cooperación a los compañeros del Sindicato Unidos Portuarios Argentinos en toda ocasión que le fue requerida"; ${ }^{23}$ por otra parte pedía a los trabajadores de Bahía Blanca en su conjunto "mantener la mayor disciplina" en la emergencia, sin tomar ninguna actitud que no fuera avalada desde la CGT. De esa forma convocaba a una reunión el 9 de enero, para discutir la situación de la central con los distintos secretarios generales de gremios locales. La reunión, que finalmente se hizo el 10 en el local de la seccional de la Federación Argentina Sindical de Petroleros, no tuvo éxito de concurrencia. Solo se presentaron cinco dirigentes de la mesa directiva y no se llegó a formar el plenario. ${ }^{24}$ Ese mismo día en

de la agrupación portuaria peronista Unidad y Lucha -que nació localmente al calor de la huelga y con una posición antiburocrática y clasista-. Asimismo, carecemos de fuentes que nos permitan reconstruir otro tipo de presencia de organizaciones de izquierda en el marco de este conflicto (algo que -cabe aclarar-sí sucedió para otros puntos del país), no obstante no deberiamos descartar la posibilidad de acciones de entrismo en sectores del peronismo más activos en esta lucha, ya que organizaciones como Palabra Obrera estaban teniendo presencia en la ciudad ya entonces (Pozzi, 2001: 19). Y, como bien señala Julia Giménez, "la primigenia organización de Palabra Obrera en Bahía Blanca se asentó en diversos sectores productivos (industria metalúrgica, ferrocarril, puerto) y también educativos de la ciudad. La trayectoria de Palabra Obrera desde fines de los años 1950 y principios de 1960 estuvo marcada por la formación de cuadros y la práctica entrista en el movimiento peronista" (2008: 18). 22. LNP, 8 de enero de 1967.

23. Ibídem.

24. Fondo documental Prefectura Naval Zona Atlántico Norte (PNZAN), memorando X.Z. an. (I), n 5, “C”, 967, 11 de enero de 1967. 
White, los afiliados del SUPA hicieron otra reunión en la cual se discutió acaloradamente cómo continuar con las medidas adoptadas. Algunos mocionaron levantar la huelga. Esta moción fue acallada con insultos y amenazas por parte de los que querían sostenerla. Se terminó aprobando una declaración respecto a la toma de la CGT. En el comunicado pedian: "convocar un plenario de Secretarios Generales, con facultades resolutivas y al mismo tiempo ordenar a los ocupantes de la CGT que una hora antes de realizarse el plenario desalojen el mismo en forma pacífica". ${ }^{25}$ En simultáneo los portuarios ocupantes emitieron otro comunicado, en el cual criticaban al gobierno por sus medidas económicas, también por la intervención del SUPA Central, y repudiaron a la CGT -tanto a nivel local como nacional- por ser dirigentes "negociadores con el régimen". ${ }^{26}$

El 11 de enero, luego de estar cuatro días tomando la central y bajo la promesa de un plenario para tratar el tema de la huelga, los portuarios dejaron la CGT. Se realizó un pequeño acto del cual fue orador Luis Leiva, secretario general de la Unión Ferroviaria de White y amigo personal de Ismael Paiz. Leiva apoyó a los estibadores ${ }^{27}$ y criticó la apatía de la CGT regional frente a la huelga que ya llevaba 82 días. Uno de los portuarios ocupantes señaló que habían logrado la promesa de un plenario de gremios donde se tratarian todos sus reclamos. ${ }^{28}$ Alli se resolvió designar una comisión para que realizara "gestiones ante los poderes públicos de la Capital Federal con el objeto de buscar una solución al problema portuario". ${ }^{29}$

En este contexto, el capitán Ochoa fue consultado por el diario $L a$ Nueva Provincia al respecto de si se reconoceria la vigencia del turno rotativo vigente en el convenio colectivo 1/61; el militar respondió que desconocía esa resolución y que no tenía ninguna orden de sus superiores de aplicarla. También sostuvo que "las disposiciones relativas al trabajo que se efectúa en los puertos nacionales emanan de la superioridad y que rigen en todas las estaciones maritimas del país". ${ }^{30}$ Con esa declaración Ochoa dejaba en claro que no se volvería a aplicar el turno rotativo como sistema de contratación en el puerto de Ingeniero White.

\section{Ibídem.}

26. Ibídem.

27. Los diversos apoyos de la comunidad whitense y bahiense se solían agradecer en el espacio asambleario de los portuarios, esas expresiones registradas se asimilaban a ésta: "Nuestra lucha está triunfando, las innumerables adhesiones recibidas de gremios, sectores estudiantiles, y la de la población toda de Bahía Blanca". Cfr. Fondo PNZAN, memorando X.Z. an. (I), nº 5, “C”, 967, 11 de enero de 1967.

28. LNP, 12 de enero de 1967.

29. LNP, 13 de enero de 1967.

30. LNP, 11 de febrero de 1967. 
El 19 de marzo de 1967 se realizó una asamblea de 400 estibadores. Luego de casi 150 dias de huelga sin haber podido lograr la reinstauración del turno rotativo ni ningún cambio respecto a la reestructuración portuaria, la medida ya había sufrido un fuerte desgaste que se expresó en la decisión de levantar el paro por amplia mayoria. ${ }^{31}$ Luego de conocerse la decisión de esa asamblea, la Capitanía de Puertos puso a disposición una planilla (controlada por la Prefectura Nacional Marítima) para que los estibadores que quisieran ingresar a trabajar se anotaran alli. Aunque se aclaró que tendrian prioridad de ingreso al trabajo aquellos que habian estibado durante la huelga. ${ }^{32}$ De esta manera la Capitanía de Puertos concretó el desplazamiento de los portuarios huelguistas. El no ingreso al puerto fue una de las marcas más fuertes que dejó esta medida de fuerza derrotada.

Y porque llegaron los militares y pusieron la Capitanía de Puerto y ya era todo mucho más controlado, a la gente que había estado en la huelga nos hacían cruces, no les daban las libretas de trabajo, no los dejaban trabajar. A mí no porque yo era chico, pero por ejemplo a dirigentes se tuvieron que ir y no pudieron trabajar más. ${ }^{33}$

Sí, porque el que estaba en la Prefectura me tildó de comunista. Y todos iban entrando de a poquito, pero yo no pude entrar más al puerto... yo era el presidente de la cooperativa ${ }^{34}$ y no pude entrar más al Puerto. ${ }^{35}$

\section{Marcas de la huelga. Los aprendizajes y las nuevas demandas}

La prohibición de ingreso al puerto luego de la huelga fue un hecho que quedó marcado en la memoria de los trabajadores, y fue recordado por muchos de los que quedaron fuera como el desenlace final de esta

31. LNP, 20 de marzo de 1967.

32. Ibídem.

33. Entrevista de la autora a Carlos Florido (estibador), 21 de septiembre de 2012.

34. Se refiere a la Cooperativa Obrera Portuaria de Estibajes Limitada de Bahía Blanca, empresa cooperativa de los estibadores que trabajaba exclusivamente con los buques que le correspondian a la Junta Nacional de Granos. Se constituyó el 11 de mayo de 1961 con el objetivo, de eliminar intermediarios frente al trabajo de carga y descarga de buques para la JNG. En ella los estibadores trabajaban con control tarifario y luego se distribuía el noventa por ciento de las utilidades logradas entre los miembros de forma trimestral.

35. Entrevista de la autora a Humberto Danuzio (estibador), 13 de diciembre de 2012. 
lucha. Sin embargo el reclamo por el turno rotativo no fue dejado de lado. Muy por el contrario, encontramos registros de que desde el SUPA se continuó impulsando esta demanda por años, pero ya desde los canales de las nuevas negociaciones colectivas posteriores a la huelga. Esta demanda fue encarada desde la comisión directiva del SUPA -que ya no encabezaba Ismael Paiz sino su sucesor, Néstor Rodríguez, o "El paritario" Rodríguez, como lo llamaron siempre los estibadores-. ${ }^{36}$

Desde el gremio se había presentado en 1971 un anteproyecto para lograr la reimplantación del turno rotativo en la contratación de personal, este anteproyecto tenía fecha del 8 de marzo de $1971 .{ }^{37} \mathrm{El} \mathrm{mismo} \mathrm{se}$ habia incorporado al Expediente $n^{\circ} 87.019 / 71$ de la Comisión Paritaria del Gremio Portuario. En este anteproyecto, no solo aparecía el reclamo por la reinstauración del turno, sino también el registro de lo que significaba este mecanismo para los estibadores y lo que había representado para ellos que les quitaran esa forma de organización en 1966. En dicho expediente figuraban una gran cantidad de volantes y solicitudes del SUPA contra "la inhumana y arbitraria modalidad de trabajo impuesta a partir del año 1966". La derrota de la huelga de 150 días había dejado marcas que se resignificaban con el paso del tiempo. Los representantes paritarios plantearon una línea de continuidad entre el saldo que había dejado esta huelga para los trabajadores y sus reclamos en paritaria que -explicaban- se remitian a aquel conflicto de su historia reciente.

Pero la pelea concreta ya no era sólo por la devolución del turno rotativo, ellos ahora luchaban por lo que llamaban un "puerto-fábrica". Es decir, la institucionalización de planteles estables de trabajadores portuarios. En primera instancia, las propuestas de los paritarios whitenses fue no supeditar la lógica local del puerto a medidas "centralistas" como establecían los Centros de Contrataciones al estilo de los existentes en el puerto de Buenos Aires; porque, afirmaban, "si implantamos el sistema de los Centros de Contratación de mano de obra existente en Capital Federal, en un Puerto estacional como el nuestro, donde durante meses su actividad es casi nula, provocariamos un hecho cuyas derivaciones resultarian absolutamente negativas". ${ }^{38}$ También explicaban que ellos no iban a aceptar nuevamente una división entre trabajadores "selectivos y ocasionales", es decir, trabajadores con un jornal fijo y trabajadores de presencia eventual. Los aprendizajes respecto a experiencias pasadas se podian visibilizar aquí. La lucha que se había dado durante la huel-

36. Durante el año 1972 Néstor Rodríguez como secretario del SUPA de Ingeniero White estuvo frente a la negociación paritaria del sector en la zona.

37. Fondo PNZAN, memorando 8687, MBI n 39, "C", 972, 13 de julio de 1972. También el "anteproyecto" aparece anexo en el CCT SUPA n $139 / 73$.

38. Ibídem. 
ga -y también antes de ella- entre afiliados "con numero" y "changas" (ocasionales) los había preparado para no volver a cometer antiguos errores (Zapata, 2014: 186-192). La demanda explícita era por estabilidad laboral para todos sin distinciones. Es decir "el puerto-fábrica", como ellos lo llamaban:

Nuestro sindicato sostiene que los personales que trabajen en la estiba portuaria, son producto de una profesión, y que por lo tanto deben adoptarse los recaudos necesarios para transformar el Puerto en una verdadera fábrica, donde el auténtico portuario, tenga asegurado su trabajo, con derechos y obligaciones perfectamente determinados. El Puerto debe dejar de ser tierra de aventura. Es necesaria la vigencia de normas claras y controles efectivos que termine con la anarquía y el abuso, que enervan el derecho de los auténticos trabajadores, comprometen la economía y el prestigio del empresario responsable y diluyen la imagen de la autoridad portuaria.

Es menester terminar con procedimientos aberrantes, que ofenden la dignidad del trabajo, como la de los capataces buscando en lugares de expendio de bebida mano de obra con que integrar sus equipos o el empleo de personas extra portuarias que, a cambio de una retribución, muchas veces inferior a la que marcan los convenios vigentes, o eludiendo cargas sociales, se prestan a prácticas desleales. ${ }^{39}$

El puerto debía dejar de ser "una aventura": esto reclamaban los trabajadores. Demandaban formalidad en la contratación y el fin de la precariedad a la que los tenían acostumbrados. Reclamaban por los derechos y las obligaciones de cualquier trabajador contenido formalmente en un espacio de trabajo distinto al puerto, caracterizado por la inestabilidad e incertidumbre laboral.

Las exigencias precisadas dentro del anteproyecto eran: 1) el establecimiento del turno rotativo como forma de contratación; 2) la formación de una Comisión Tripartita (entre Estado, empleadores y obreros) a cuyo cargo se encontrara todo lo inherente a la aplicación del primer punto; 3) las normas respectivas para un efectivo control del los aportes con destino a las cajas de previsión de asignaciones familiares y al Instituto de asistencia social del estibador, y 4) el agrupamiento de los estibadores en planteles por especialidad y lugar de trabajo.

Más allá de lo relevante de estas demandas, finalmente en la negociación las mismas no fueron concedidas. Y el anteproyecto propuesto por el SUPA no se vio reflejado dentro del convenio que se terminó ho- 
mologando. La negativa de las autoridades militares quedó evidenciada cuando el capitán de puerto de Bahía Blanca, capitán de navío Jorge Rodríguez, envió una carta al Ministerio de Trabajo el día 24 de noviembre de 1971 donde sostenía que si bien entendía los lógicos reclamos salariales, sobre la cuestión del turno rotativo no delegaria la decisión y especificaba: "el turno rotativo de contratación es un problema a resolver por la autoridad competente, en este caso esta Capitanía de Puerto"..$^{40}$ Luego de estas infructuosas negociaciones para el sector trabajador, el convenio 139/73 entre el SUPA y la Cámara Portuaria Marítima de Bahía Blanca resultó beneficioso solo para los empresarios. Respecto a la recomposición salarial, solo se aumentó un $37 \%$ cuando el SUPA había pedido un aumento del $100 \%$. Y de las demandas referidas a la reimplementación del turno rotativo, formas de contratación, comisión tripartita y aportes previsionales, no se llegó a concretar ninguna de ellas. ${ }^{41}$

Las firmes posiciones de los funcionarios militares se fundamentaron en las presiones de empresarios que no aceptaban desistir ante el control del acceso al trabajo. En registros de finales de 1971, los servicios de inteligencia de Prefectura explicaban que esa reforma "daría lugar a los vagos" y a la merma del trabajo "ya que el personal de estiba trabaja sin preocupación por contar seguro con volver a trabajar cuando le toque otra vez el turno y no como antes que corría el peligro de no entrar nuevamente si su rendimiento no era normal y no estaba conforme la agencia contratista". ${ }^{42}$

La negativa tenía que ver con negar el control del acceso democrático al trabajo a los estibadores ya que, con éste, la patronal entendía que se perderia rentabilidad. Sin el turno rotativo, eran las empresas de estiba las que tenían suficiente margen de decisión para elegir a los portuarios que considerara "más eficientes".

\section{A modo de cierre}

Se suele considerar que los estudios sobre historia local amplian el estado de conocimiento sobre un tema particular. Sin embargo -y más allá de los "datos locales nuevos" que pudieran resultar un aporte sobre

40. Fondo documental Ministerio de Trabajo y Seguridad Social (en Archivo Intermedio, AGN) y CCT-SUPA Bahía Blanca (1973) n¹39/73.

41. Con posterioridad a este contexto dictatorial, encontramos fuentes que referencian la recuperación del turno rotativo hacia el año 1974, ya con gobierno constitucional y otra gestión gremial dentro del SUPA, la del secretario general Emiliano Osores. Cfr. Administración General de Puertos, Puerto de Bahía Blanca 1974-1975: 61.

42. Fondo PNZAN, memorando 8687, MBI n 143, 971, 19 de noviembre de 1971. 
el desarrollo de esta huelga portuaria tan significativa para la épocaquisimos presentar en este trabajo algunas de las potencialidades de estos enfoques a la hora de complejizar interpretaciones "macro" respecto de un proceso histórico de alcance nacional, cuando se problematiza la cuestión de la escala de análisis.

Observamos por un lado que este tipo de abordaje permite analizar la trasmisión de experiencias de lucha entre los actores y cómo la misma se juega en los pasajes de escala (nacional o local) y se condensa muchas veces en aquellos actores que viajan literalmente, entre una localidad y otra, funcionando como vectores de comunicación de ciertas prácticas y repertorios de formas de protesta u organización. (Zapata, 2014: 177) Por otro lado, observamos que al reconstruir un proceso de lucha atendiendo a las escalas de análisis, podemos advertir temporalidades específicas y contrastantes respecto de un mismo proceso histórico. Y también, asistir a disimiles resoluciones del mismo. Es un dato que esta huelga nació en contra de medidas tomadas en el orden de lo nacional, pero fue sostenida en el orden local desde otras que complejizaron ese reclamo original.

Todos estos aspectos nos advierten respecto de los problemas que trae aparejado el no asumir explícitamente la escala espacial que se aborda: consideramos que el análisis de escalas resulta una elección metodológica que debería estar explícita de antemano para evitar que posteriormente se "nacionalice" una interpretación que solo alude a tal o cual ciudad o región. Sobre todo pensando en los aportes historiográficos que pueden traer estos estudios, al respecto Águila advierte que:

En nuestro país la construcción de una historiografia renovada estuvo vinculada, entre otros desarrollos, a los estudios regionales y locales. Ello ha sido muy visible para momentos donde la integración nacional aún era débil o donde las realidades y articulaciones regionales ostentaron rasgos diferenciados, particularmente en el siglo XIX y los inicios del siglo XX. (Águila, 2015: 92)

En este artículo también buscamos mostrar diferentes aristas de un proceso de lucha que dejó marcas subjetivas en los trabajadores portuarios whitenses, así como también signó parte de la historia social y económica de la ciudad y la zona. El régimen de "racionalización" portuaria afectó no solo la cotidianidad laboral y las conquistas previas de los estibadores, sino que también inauguró nuevas condiciones de trabajo caracterizadas por un espacio militarizado y supeditado a restrictivas formas de acceso al puerto, sobre todo para aquellos estibadores que habían participado de la huelga. En este sentido, debemos leer los 
cambios productivos del trabajo, vinculados a las situaciones de persecución de la actividad gremial o política y represión que la dictadura de Onganía significó para algunos sectores del movimiento obrero organizado. La quita del turno rotativo y el nuevo régimen de puertos, sumado a la derrota tras 150 días de huelga y a la consecuencia de no poder ingresar al trabajo por años debido a estar marcados y estigmatizados como huelguistas, representaron marcas insoslayables que afectaron por años la vida de los portuarios whitenses. ${ }^{43}$

Sin embargo, también encontramos que esta lucha dejó marcas en términos de aprendizajes e iniciativas relevantes para la organización obrera y de base. La toma de la CGT regional -llevada a cabo incluso al margen de las medidas de fuerza a nivel nacional- fue expresión de lo anterior. También lo fueron las instancias de posterior resignificación de los reclamos de la huelga, con una puja de negociación de convenio en años posteriores. Las nuevas aspiraciones fueron una apuesta mayor que llegó incluso al reclamo por la institucionalización de formas de trabajo y contratación que aseguraran mayores derechos y estabilidad en el trabajo portuario.

\section{Bibliografia}

Águila, Gabriela (2008), "La dictadura militar argentina: interpretaciones, problemas, debates", Páginas. Revista digital de la Escuela de Historia, año $1, \mathrm{n}^{\circ} 1$, Rosario.

- (2015), "Las escalas de análisis en los estudios sobre el pasado reciente: a modo de introducción”, Avances del Cesor, Rosario, año XII, $\mathrm{n}^{\circ} 12$, pp. 91-96.

Bandieri, Susana (2008), "La dimensión regional como alternativa analítica para pensar otros espacios y nuevas periodizaciones", en Susana Bandieri, Graciela Blanco y Mónica Blanco (coords.), Las escalas de la historia comparada, Buenos Aires: Miño y Dávila.

Berrotarán, Patricia (2000), "La privatización y los trabajadores del puerto de Buenos Aires (1991-1996)", en Hernán Camarero, Pablo Pozzi y Alejandro Schneider (comps.), De la Revolución Libertadora al menemismo, Buenos Aires: Imago Mundi.

Caruso, Laura (2013), "La organización sindical del sector marítimo: tra-

43. Un síntoma de esto último se evidenció en el contexto de algunas de las entrevistas cuando, frente a preguntas específicas respecto de las vivencias en White durante la dictadura de 1976, muchos portuarios remitieron desde su memoria al contexto dictatorial previo, es decir la dictadura de Juan Carlos Onganía. La experiencia en la huelga de 1966 apareció como un hito más presente y angustiante, en especial en los casos en que significó la baja laboral y la prohibición de ingreso al puerto por estar "marcados" por huelguistas. 
bajadores de ríos y mares, sus luchas y asociaciones", en Revista de Estudios Marítimos y Sociales, año 5/6, Mar del Plata.

Dagnino Pastore, José María (1968), "Discurso, 31 de agosto 1968", en Bahía Blanca Polo de desarrollo, Ministerio de Economía de la Provincia de Buenos Aires, La Plata.

Giménez, Julia (2008), "Ciudad de perros. Historias de militancia y recorridos del PRT-ERP por la ciudad de Bahía Blanca”, tesis de Licenciatura, Departamento de Humanidades, Universidad Nacional del Sur.

James, Daniel (1990), Resistencia e integración. El peronismo y la clase trabajadora argentina, 1946-1976, Buenos Aires: Sudamericana.

Jensen, Silvina (2010), "Diálogos entre la historia local y la historia reciente en la Argentina. Bahía Blanca durante la última dictadura militar", en Actas del XIV Encuentro de Latinoamericanistas Españoles, Universidad de Santiago de Compostela.

Jensen, Silvina y Soledad Lastra (2015), "El problema de las escalas en el campo de estudio de los exilios políticos argentinos recientes", Avances del Cesor, Rosario, año XII, n ${ }^{\circ} 12$, pp. 97-115.

Ladeuix, Juan Iván (2009), "Descubriendo los puertos. Apuntes sobre la legislación marítima y la regulación del sistema portuario argentino, 1941-1949", Revista de Estudios Maritimos y Sociales, año II, n² 2, Mar del Plata.

Nassif, Silvia (2012), Tucumanazos. Una huella histórica de luchas populares 1969-1972, San Miguel de Tucumán: Ed. UNT.

O’Donnell, Guillermo (2009), El Estado burocrático autoritario, 1966-1973. Triunfo, derrotas y crisis, Buenos Aires: Prometeo.

Pozzi, Pablo (2001), “Por las sendas argentinas...”. El PRT-ERP. La guerrilla marxista, Buenos Aires: Eudeba.

Pozzi, Pablo y Alejandro Schneider (2000), Los setentistas, la izquierda y la clase obrera 1969-1976, Buenos Aires: Eudeba.

Rodríguez Agüero, Laura (2013), "Ciclo de protestas, experiencias organizativas y represión paraestatal. Mendoza, 1972-1976”, tesis de Doctorado en Historia, Universidad Nacional de La Plata, Facultad de Humanidades y Ciencias de la Educación.

Scatizza, Pablo (2013), "La Norpatagonia argentina bajo la Doctrina de Seguridad Nacional. Represión, dictadura y juicios de lesa humanidad: la causa Reinhold", tesis de Doctorado en Historia, Universidad Torcuato Di Tella.

Schneider, Alejandro (2005), Los Compañeros. Trabajadores, izquierda y peronismo, 1955-1973, Buenos Aires: Imago Mundi.

Snitcofsky, Valeria (2011), "Villas de Buenos Aires y conflictos portuarios bajo el gobierno de Onganía: aportes para un análisis de la articulación entre sindicalismo de base y organización territorial", en Victoria Basualdo (coord.), La clase trabajadora Argentina en el siglo XX: experiencias de lucha y organización, Buenos Aires: Cara o Ceca.

Zapata, Ana Belén (2014), "Andamios de experiencias: Conflictividad obrera, 
vigilancia y represión en Argentina. Bahía Blanca, 1966-1976”, tesis de Doctorado en Historia, Universidad Nacional de La Plata, Facultad de Humanidades y Ciencias de la Educación.

- (2015) "Pensar la escalada de violencia y la violencia en escalas. Entramados de la "lucha antisubversiva" predictatorial. Bahía Blanca, 19741976”, Avances del Cesor, Rosario, año XII, n 12, pp. 141-156.

$$
* * *
$$

Titulo: Port workers's struggle: from the strike of 1966, to the claim for a "Factory-Port" in Bahía Blanca

Resumen: En este artículo analizaremos aspectos singulares en la dinámica de la huelga portuaria de 1966, en el gobierno dictatorial de Juan Carlos Onganía. Nos centraremos en la reconstrucción histórica del conflicto en el puerto de Ingeniero White, cercano a Bahía Blanca. Analizaremos los momentos de coordinación y/o disonancia en las instancias que marcaron esta lucha, en lo local, regional y nacional. Nos preguntamos ¿cuáles fueron las principales demandas locales en el marco de medidas que afectaron a distintos puertos del país durante la huelga?, ¿cómo contrastaron los momentos de la huelga entre la escala local y la nacional?, ¿cuáles fueron los efectos de ese proceso de lucha para los trabajadores a corto y largo plazo?, ¿qué aprendizajes trajo aparejada esta lucha? Palabras clave: Huelga portuaria - Ingeniero White - Onganía - Estibadores

\begin{abstract}
In this article we will analyze singular aspects in the dynamics of a port strike in 1966, in the context of the dictatorial government of Juan Carlos Ongania, in Argentina. We will focus on the historical reconstruction of this conflict specifically at Ingeniero White's port, near Bahía Blanca. We will analyze the moments of coordination /dissonance of this struggle, at the local, regional and national levels. We will start from the questions: What were the main local requests within the strike? How did the moments of the strike contrast between the local and the national scale? What were the short and long term effects of this process for the workers?, What lessons did this struggle bring to them?
\end{abstract}

Keywords: Port strike - Ingeniero White - Onganía - Port workers 